\title{
Liquid Gallium Columns Sheathed with Carbon: Bulk Synthesis and Manipulation
}

Jinhua Zhan,${ }^{*} \dagger$ Yoshio Bando, ${ }^{\dagger}$ Junqing Hu,${ }^{\star}$ Dmitri Golberg, ${ }^{\dagger}$ and Haruyuki Nakanishi ${ }^{\S}$

\section{Supporting information}

SI-Figure 1 schematic diagram of the vertical induction furnace used for the synthesis SI-Figure 2 SEM image of the product obtained at $1150^{\circ} \mathrm{C}$.

SI-Figure 3 TEM image displaying the bending of a $\mathrm{C}$ sheath under a constant 2-minute electron-beam irradiation at one nanostructure side.

SI-Figure 4 Consecutive TEM images showing that two discrete liquid Ga segments join under heating. (a) $19^{\circ} \mathrm{C}$; (b) $63^{\circ} \mathrm{C}$; (c) $343^{\circ} \mathrm{C}$; (d) $430^{\circ} \mathrm{C}$.

SI-Figure 5 TEM image showing a thermometer-like structure. 


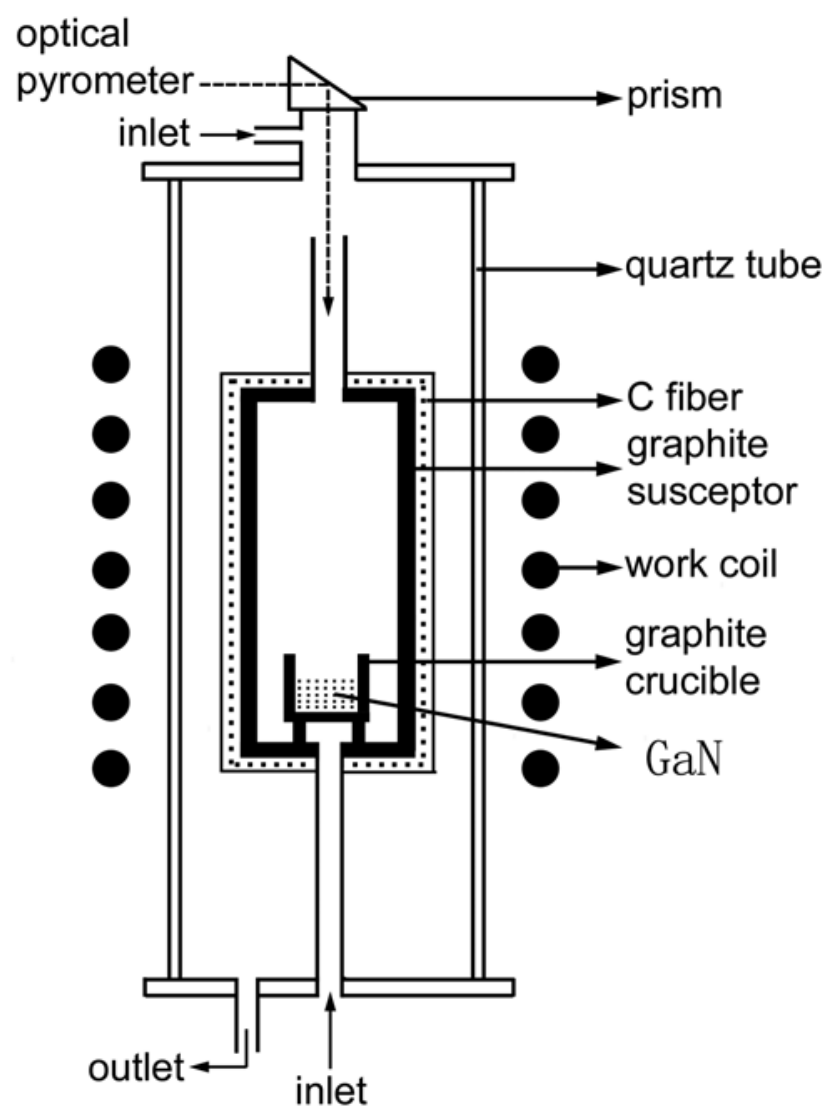

SI-Figure 1 schematic diagram of the vertical induction furnace used for the synthesis 


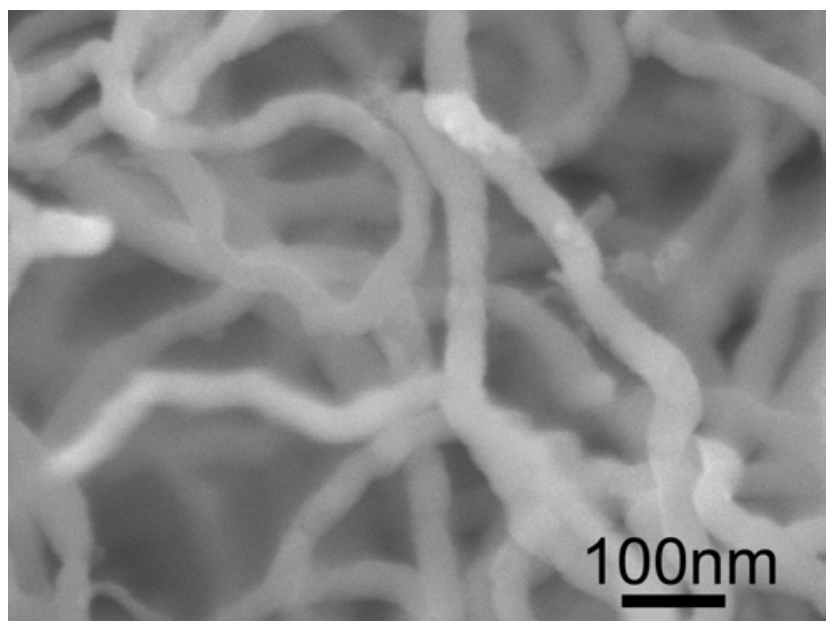

SI-Figure 2 SEM image of the product obtained at $1150^{\circ} \mathrm{C}$. 


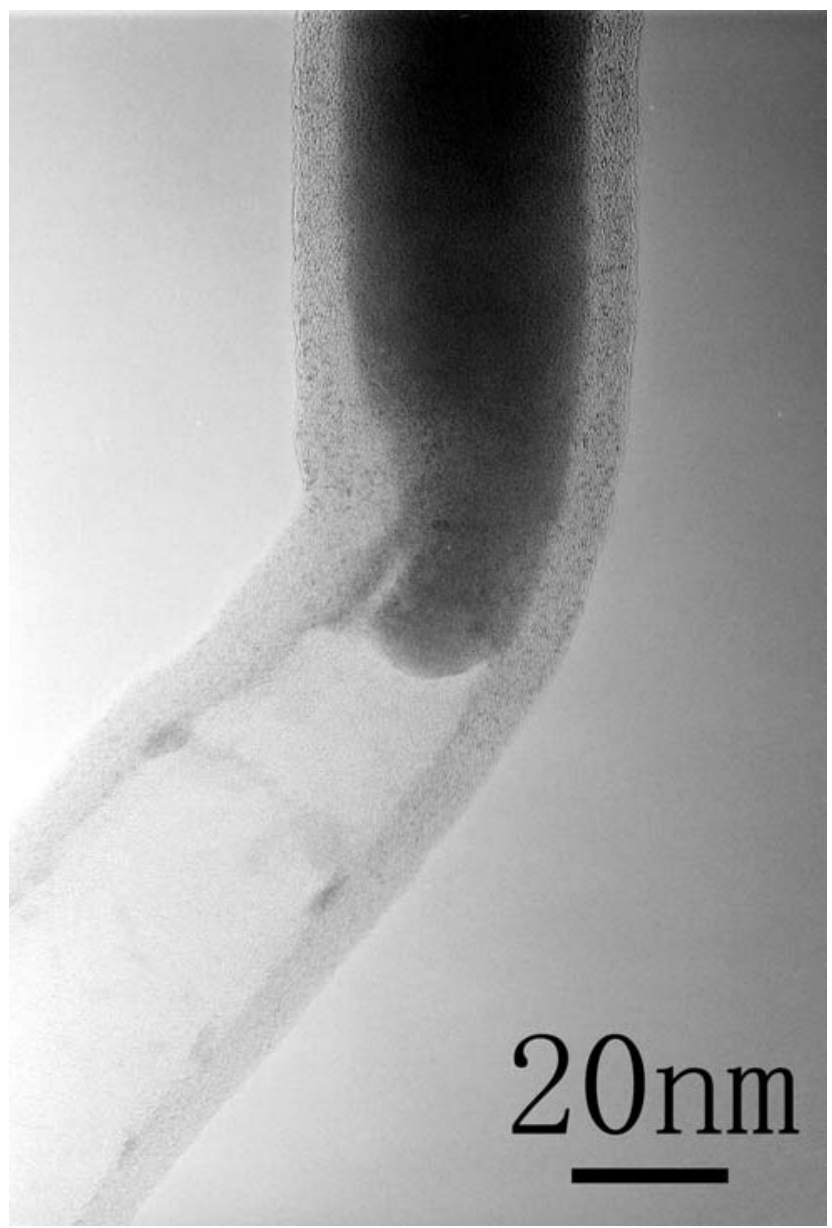

SI-Figure 3 TEM image displaying the bending of a $\mathrm{C}$ sheath under a constant 2-minute electron-beam irradiation at one nanostructure side. 


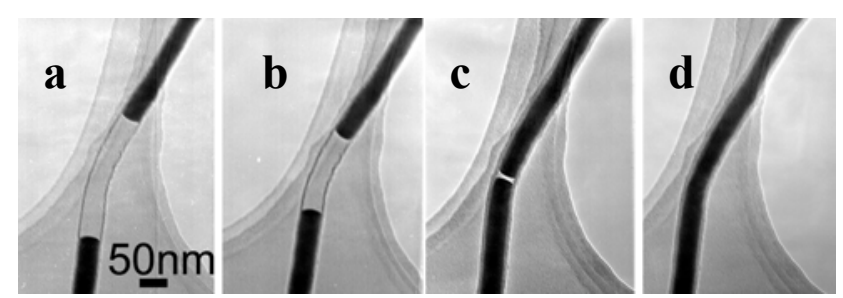

SI-Figure 4 Consecutive TEM images showing that two discrete liquid $\mathrm{Ga}$ segments join under heating. (a) $19^{\circ} \mathrm{C}$; (b) $63^{\circ} \mathrm{C}$; (c) $343^{\circ} \mathrm{C}$; (d) $430^{\circ} \mathrm{C}$ 


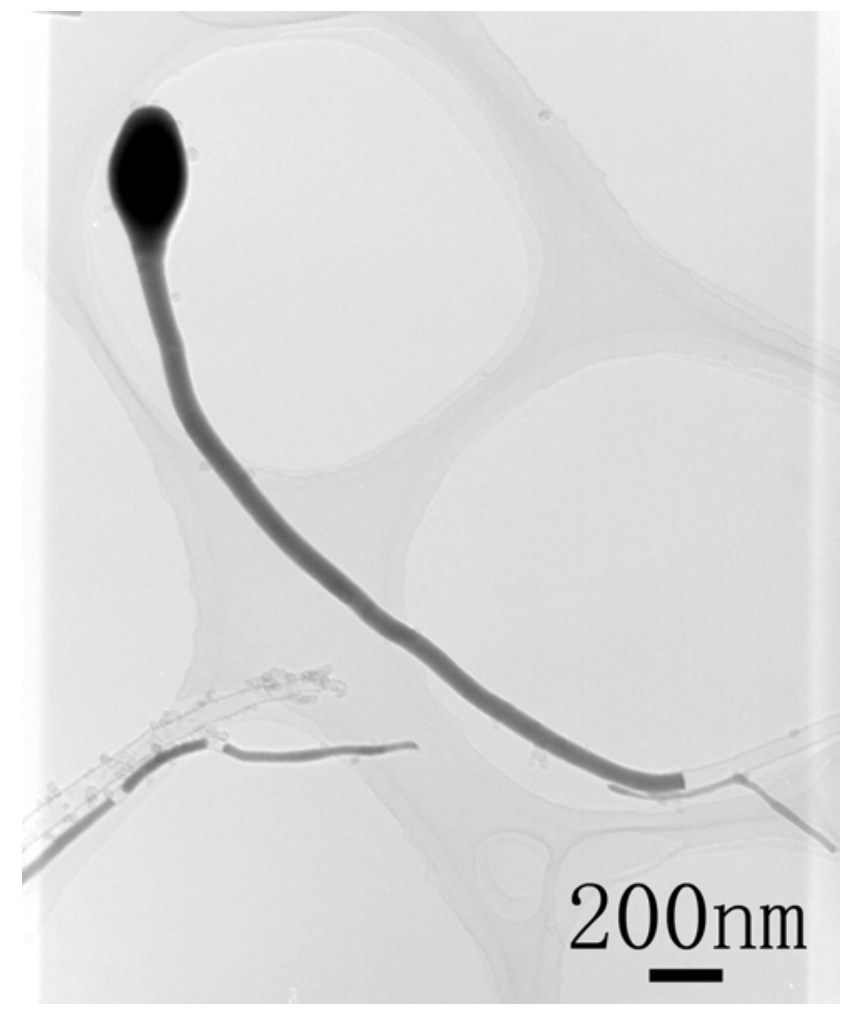

SI-Figure 5 TEM image showing a thermometer-like structure. 